OPEN ACCESS

Edited by:

Arthur Jonas Ragauskas, University of Tennessee, Knoxville,

United States

Reviewed by:

Selhan Karagoz,

Karabük University, Turkey

Ao Xia,

Chongqing University, China

${ }^{*}$ Correspondence:

Bin Yang

bin.yang@wsu.edu

Specialty section:

This article was submitted to

Bioenergy and Biofuels,

a section of the journal Frontiers in Energy Research

Received: 27 October 2017 Accepted: 24 January 2018

Published: 13 February 2018

Citation:

Qin $Y$, Wang $H$, Ruan H, Feng $M$ and Yang $B$ (2018) High Catalytic Efficiency of Lignin

Depolymerization over Low Pd-Zeolite Y Loading at Mild Temperature.

Front. Energy Res. 6:2.

doi: 10.3389/fenrg.2018.00002

\section{High Catalytic Efficiency of Lignin Depolymerization over Low Pd-Zeolite Y Loading at Mild Temperature}

\author{
Yuling Qin', Hongliang Wang', Hao Ruan ${ }^{1}$, Maoqi Feng ${ }^{2}$ and Bin Yang ${ }^{1 *}$ \\ ${ }^{1}$ Bioproducts, Sciences and Engineering Laboratory, Department of Biological Systems Engineering, Washington State \\ University, Richland, WA, United States, ${ }^{2}$ Chemistry and Chemical Engineering Division, Southwest Research Institute, \\ San Antonio, TX, United States
}

This article reported a novel low-temperature process for aromatics production through lignin depolymerization catalyzed by $0.1 \mathrm{wt} \% \mathrm{Pd}$-zeolite $\mathrm{Y}$ catalyst prepared by a facile method. Under the same reactive condition, the as-prepared $\mathrm{Pd}$-zeolite $\mathrm{Y}$ catalysts exhibited much higher catalytic efficiency than zeolite $\mathrm{Y}$ or commercial $\mathrm{Pd} / \mathrm{Al}_{2} \mathrm{O}_{3}$-zeolite composites. The selectivity of the Pd-zeolite $\mathrm{Y}$ toward lignin depolymerization was also much higher than the other commercial zeolite-based catalysts. With the presence of hydrogen, aromatics were the predominant products with high yields of phenols and dimers (over 99\%). The as-obtained aromatics can be promising feedstock for production of fuels or chemicals for various applications. Results revealed that the Pd-zeolite $Y$ catalyst is a highly active catalyst for the cleavage of lignin interlinkages, especially the $\mathrm{C}-\mathrm{O}-\mathrm{C}$ bonds by hydrogenolysis.

Keywords: lignin conversion, biomass, Pd, zeolite, phenols, aromatics, high efficiency and selectivity

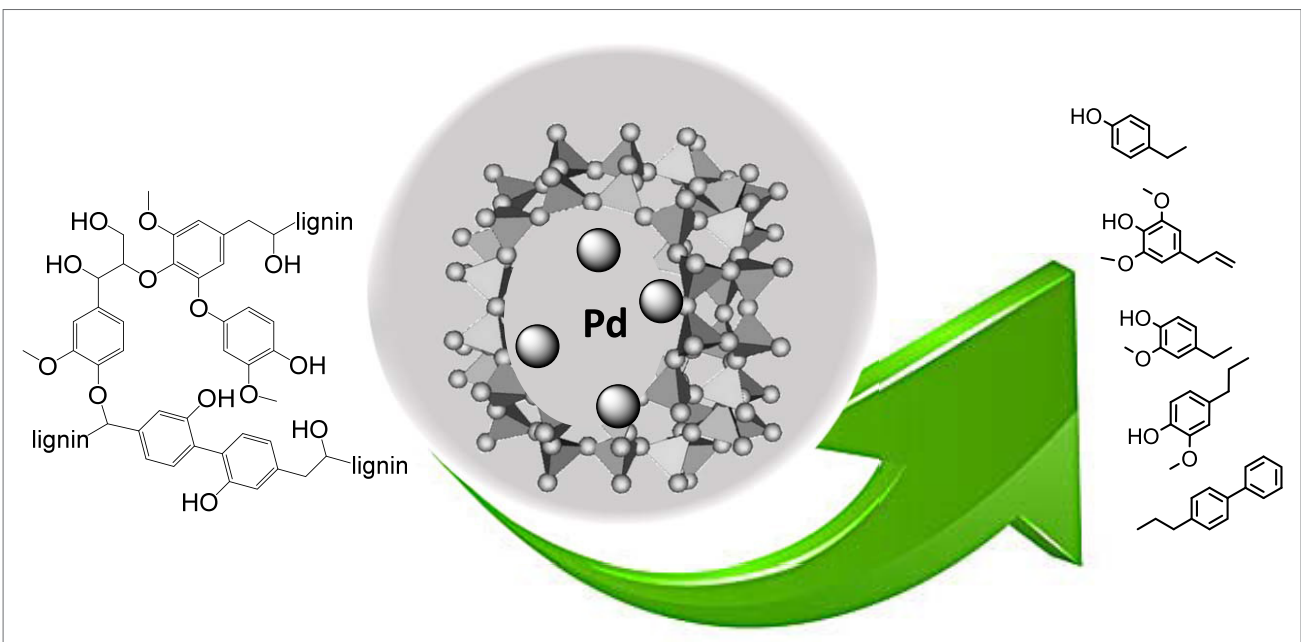

GRAPHICAL ABSTRACT | High catalytic efficiency of lignin depolymerization over low Pd-zeolite Y loading at mild temperature. 


\section{INTRODUCTION}

Catalytic conversion of biomass lignin into value-added chemicals and fuels is a promising route to resolve the energy crisis (Jae et al., 2010; Ragauskas et al., 2014; Kong et al., 2015; Wang et al., 2016). Nevertheless, state-of-the-art lignin utilization technologies still face tremendous challenges, including depolymerization and upgradation, especially the catalytic depolymerization process (Alonso et al., 2010; Xu et al., 2014; Li et al., 2015; Yang et al., 2015). Among various catalysts for lignin depolymerization, zeolites are widely accepted due to their low-cost, high surface area, and outstanding acid sites catalytic performance (Taarning et al., 2011; Ben and Ragauskas, 2012; Wang et al., 2017). External Brønsted acidity in meso-/microporous zeolites was reported to effectively affect the selectivity of de-alkylation and de-etherification reactions in parallel during lignin conversion (Taarning et al., 2011; Singh and Ekhe, 2014; Deepa and Dhepe, 2015). Deepa reported that aromatic monomers were the predominant products using zeolite as solid acid catalysts for lignin depolymerization at $250^{\circ} \mathrm{C}$ in $\mathrm{H}_{2} \mathrm{O} / \mathrm{CH}_{3} \mathrm{OH}$ mixture (Deepa and Dhepe, 2015).

However, challenges remain for catalytic lignin depolymerization by zeolites because the current zeolite-based catalysis requires high temperature $\left(250^{\circ} \mathrm{C}\right.$ or above), which leads to faster catalyst deactivation by coking and dealumination (Jia et al., 2011). Furthermore, the high temperature for solid acidcatalyzed lignin hydrolysis process possibly results in extensive side products from condensation reactions (Jia et al., 2011; Li et al., 2015). Therefore, the development of low-cost zeolite-based catalysts for lignin conversion at mild temperature will enhance lignin conversion to valuable products.

A group of catalysts with a combination of zeolite and noble metal nanoparticles drew increasing attention due to their excellent catalytic activity in lignin degradation. For example, lignin degradation and/or hydrodeoxygenation reaction were reportedly enhanced by a combination of Pt, Ru, and Pd nanoparticles supported on zeolites (Laskar et al., 2014; Wang et al., 2015). However, the complexity of the preparation of these catalysts hinders their further application.

Combining the outstanding catalytic performance of zeolites and metals, metal-exchanged zeolites potentially have higher activity than non-exchanged zeolites (Hui et al., 2010; Singh et al., 2015). The Pd metal in Pd-zeolites can become reactive sites for the cleavage of lignin bonds due to its high hydrogen-activation ability. Notably, $\mathrm{Pd}^{2+}$ ions exchanged on the zeolite frameworks appeared highly stable against metal agglomeration while maintaining high catalytic activities in hydrogen atmosphere (Choi et al., 2009). It was proposed that the catalytic reactions were carried out by the $\operatorname{Pd}(0)$ species, which was generated in situ under the tested reaction conditions. Furthermore, because of the strong metal-catalyst support interaction and pore limitation, the catalysts were reportedly stable in the zeolite pore without agglomeration (Zhang et al., 2014a).

In this study, the Pd-zeolite Y catalysts were prepared via both the facile and maneuverable ion-exchange methods for depolymerizing lignin at relatively low temperatures $\left(180-200^{\circ} \mathrm{C}\right)$. We studied catalytic activity and selectivity of these catalysts on depolymerization of alkali lignin compare with zeolite alone and commercial Pd/ $\mathrm{Al}_{2} \mathrm{O}_{3}$-zeolite composite catalysts (with more Pd loading) and Pd-zeolite Y catalyst (with the synergistic effect of palladium and zeolite $\mathrm{Y}$ ). The mechanism of Pd-zeolite catalysis of lignin conversion was explored. It was found that the high efficiency of surficial Pd atoms and the synergistic effects between $\mathrm{Pd}$ and zeolite $\mathrm{Y}$ played critical roles in lignin depolymerization and conversion.

\section{EXPERIMENTAL}

\section{Preparation of Pd-Zeolite $\mathbf{Y}$}

CBV 300 purchased from Zeolyst International was heated in air at $550^{\circ} \mathrm{C}$ for $5 \mathrm{~h} . \mathrm{Pd}\left(\mathrm{NO}_{3}\right)_{2}$ (Aldrich) was dissolved in diluted aqueous $\mathrm{HNO}_{3}(0.01 \mathrm{M})$ solution. Then $1 \mathrm{~g}$ of zeolite (CBV300) was dispersed into $50 \mathrm{~mL}$ of water solution by stirring, followed by adding aqueous $\mathrm{Pd}\left(\mathrm{NO}_{3}\right)_{2}$ solution [containing $5 \mathrm{mg}$ of $\left.\mathrm{Pd}\left(\mathrm{NO}_{3}\right)_{2}\right]$. Stirring continued for $30 \mathrm{~min}$. Then $20 \mathrm{mg}$ of $\mathrm{NH}_{4} \mathrm{NO}_{3}$ was added, followed by stirring for another $2 \mathrm{~h}$. The mixture was then centrifuged and thoroughly washed with distilled water. The precipitate was dried at room temperature before catalytic reaction tests. Commercial $\mathrm{Pd} / \mathrm{C}(5 \mathrm{wt} \%)$ was purchased from Aldrich.

\section{Lignin Depolymerization in a Parr Reactor}

For a typical catalytic depolymerization experiment, $30 \mathrm{~mL}$ of deionized water was added into a $100 \mathrm{~mL}$ Parr reactor as solvent for the reaction, followed by adding $200 \mathrm{mg}$ of lignin and $200 \mathrm{mg}$ of Pd-zeolite catalysts. After sealing the vessel, $\mathrm{H}_{2}$ was used to flush out the air in the reactor at least four times, and then the reactor was pressurized to $3.5 \mathrm{MPa}$ at room temperature. The reactor was heated to reach the reaction temperature $\left(180-200^{\circ} \mathrm{C}\right)$ where the reaction time was started. The reaction was conducted for $3 \mathrm{~h}$. Then the vessel was plunged into cold water to cool the reaction system. Ethyl acetate was used to extract products while the $0.5 \mathrm{wt} \%$ of toluene (in ethyl acetate) was added as an internal standard. Then a sample was acquired from the organic phase for GC-MS analysis. For GC-MS analysis, the response factor for each product was standardized with the use of efficient carbon number (Scanion and Willis, 1985; Zhang et al., 2014b), which enabled the analysis of compounds without pure standards.

\section{GC-MS Analysis and Structural Analysis of Catalysts}

After ethyl acetate extraction, the organic phase was analyzed by GC-MS. $1 \mu \mathrm{L}$ of sample was injected with $0.6 \mathrm{~mL} / \mathrm{min}$ of $\mathrm{He}$ (carrier gas) into a DB-5 (30 m length $\times 250 \mu \mathrm{m}$ I.D. $\times 0.25 \mu \mathrm{m}$ film thickness, J\&W Scientific) capillary column installed in an Agilent Technologies 7890A GC that was set at splitless mode. The GC oven was set to maintain $45^{\circ} \mathrm{C}$ for $2 \mathrm{~min}$, then heated to $200^{\circ} \mathrm{C}$ at the rate of $15^{\circ} \mathrm{C} / \mathrm{min}$ then held at $200^{\circ} \mathrm{C}$ for another $1 \mathrm{~min}$. After that, the oven was heated up to $300^{\circ} \mathrm{C}$ at the rate of $10^{\circ} \mathrm{C} / \mathrm{min}$ and held for $5 \mathrm{~min}$. Eluting compounds were determined using a MS (Agilent Technologies 5975C) inter XL EI/CI MSD with a triple axis detector and matched to NIST GC-MS libraries (Wang et al., 2017). 


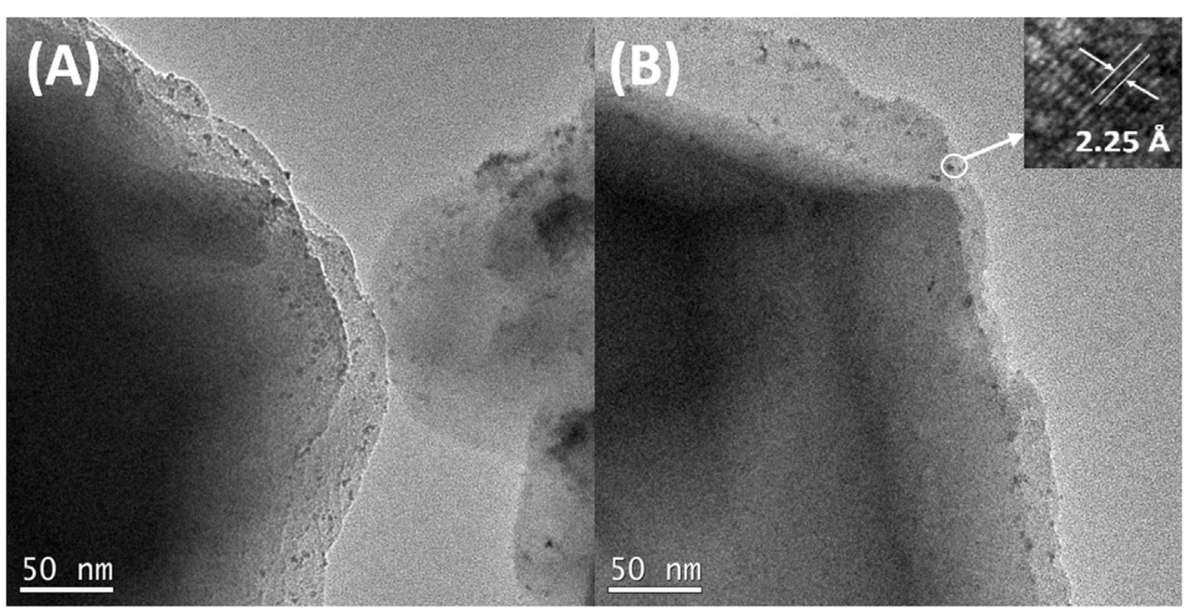

FIGURE 1 | Transmission electron microscopy images of $\mathrm{Pd}$-zeolite $\mathrm{Y}$ before $\mathbf{( A )}$ and after (B) $\mathrm{H}_{2}$ treatment under $200^{\circ} \mathrm{C}$. Inset in panel (B): high-resolution transmission electron microscopy image of $\mathrm{Pd}$ nanoparticle on zeolite $\mathrm{Y}$.

Scanning electron microscopy (SEM) analysis was performed using a field emission SEM instrument (Hitachi S-4800), operating at an accelerating voltage of $10 \mathrm{kV}$. Transmission electron microscope analysis was performed using an FEI Tecnai G2 S-Twin instrument with a field emission gun operating at $200 \mathrm{kV}$. Inductively coupled plasma atomic emission spectroscopy (ICPAES) measurements were performed on a Thermo Jarrell Ash Atom scan Advantage instrument.

\section{Equations}

The mass yield of each product and its selectivity from lignin depolymerization were calculated as follows:

$$
\begin{aligned}
\text { Yield }_{x}(\text { wt } \%) & =\frac{\frac{\text { Mass of toluene }}{92} \times \frac{\text { area }_{x} / \mathrm{ECN}_{x}}{\text { area of toluene } / 7} \times \mathrm{MW}_{x}}{\text { Mass of lignin }}, \\
\text { Selectivity }_{x} & =\frac{\text { Yield } x}{\text { Yield of total calculated products }} \times 100 \%, \\
& \text { Toal product yield }=\sum_{n=1}^{7} \text { Yield }_{x_{n}} .
\end{aligned}
$$

\section{RESULTS AND DISCUSSION}

Transmission electron microscopy (TEM) image in Figure 1A shows that Pd-precursor dispersed very well on the surface of zeolite Y, which could enhance lignin degradation because the macromolecular lignin depolymerization reacts on the surface of the zeolite. In this study, the commercial zeolite Y, Zeolyst CBV 300 , was used as a support for Pd after thermal treatment. Clearly, Pd-precursor nanoparticles with small particle size were evenly dispersed on the zeolite, while the smaller particle size led to higher atom efficiency. As seen in Figure 1B, after the $\mathrm{H}_{2}$ treatment at $200^{\circ} \mathrm{C}, \mathrm{Pd}^{2+}$ was successfully reduced into $\mathrm{Pd}(0)$ in situ while no obvious aggregation of $\mathrm{Pd}$ was found. Furthermore, the

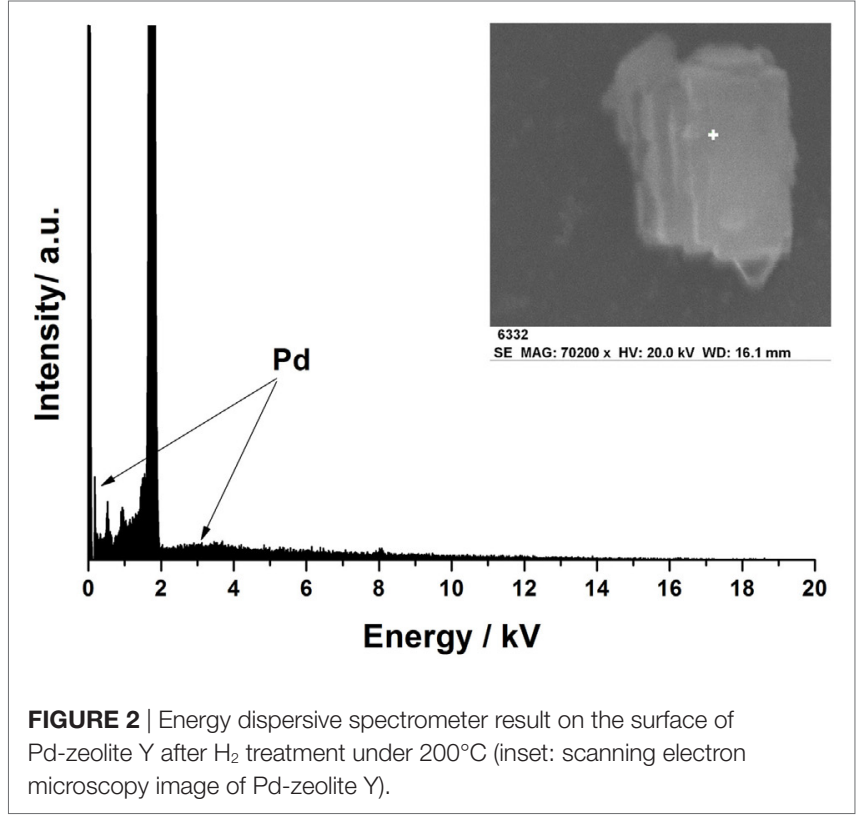

high-resolution transmission electron microscopy image of the as-obtained $\operatorname{Pd}(0)$ is shown in Figure 1B inset. The d-spacing of the nanoparticle is $\sim 2.25 \AA$, which corresponds to the (111) of $f c c \mathrm{Pd}$, indicating the existence of $\mathrm{Pd}(0)$. On the other hand, the ICP-AES results showed that the loading of Pd in Pd-zeolite was $0.1 \mathrm{wt} \%$. Due to the very low Pd loading in this catalyst, it is difficult to use the X-ray diffraction spectroscopy or X-ray photoelectron spectroscopy to prove the existence of Pd in Pd-zeolite. Therefore, the energy dispersive spectrometer (from the inset scanning electron microscope image) was further employed for the characterization of Pd. As shown in Figure 2, Pd was found from the energy dispersive spectrometer results even if its loading was low. Although the loading of Pd was quite low, it significantly improved lignin depolymerization as proved in the following lignin conversion process. 


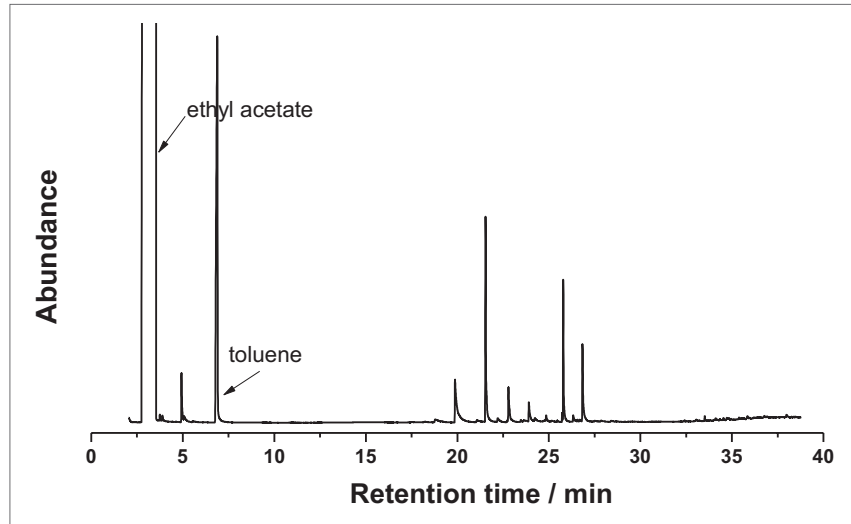

FIGURE 3 | GC-MS spectrum of the products from lignin depolymerization on Pd-zeolite $\mathrm{Y}$ at $200^{\circ} \mathrm{C}$.

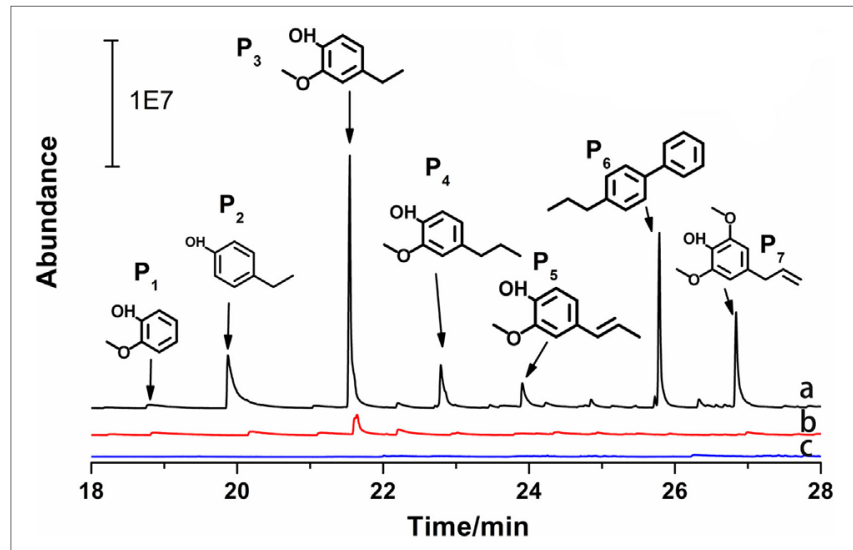

FIGURE 4 | GC-MS analysis of the products from lignin depolymerization on the three catalysts: (a) Pd-zeolite, (b) zeolite, and (c) $\mathrm{Pd}^{2+}\left[\mathrm{Pd}\left(\mathrm{NO}_{3}\right)_{2}\right.$ solution] catalysts (reaction conditions: $200^{\circ} \mathrm{C}, 3.5 \mathrm{MPa} \mathrm{H}_{2}, 3 \mathrm{~h}$ ).

The GC-MS results of the products derived from catalytic lign in conversion are concentrated in 18-28 min interval (Figure 3). In Deepa's report (Deepa and Dhepe, 2015), lignin conversion generated wide range of products from 10 to $25 \mathrm{~min}$. However, in this work, only seven products were detected by GC-MS, indicating much higher selectivity of this catalyst. Furthermore, as shown in Figure 4, phenols and substituted phenols, including guaiacols, phenol, and dimers, were the major products from lignin depolymerization on Pd-zeolite, indicating the high efficiency of the catalysts toward the cleavage of $\mathrm{C}_{\beta}-\mathrm{O}-\mathrm{C}$ and dehydroxylation on branched alkanes. In addition, no aromatic saturated products (i.e., cyclohexane and its derivatives) were observed, implying low catalytic activity of Pd-zeolite Y toward hydrogenation of aromatics. This results indicated that Pd-zeolite Y can be efficiently employed to selectively produce aromatics with wide applications in the production of useful chemicals from lignin.

Furthermore, Pd-zeolite Y showed much higher activity than both zeolite Y and Pd when they were applied separately, suggesting strong synergistic effects of Pd and zeolite $\mathrm{Y}$ on lignin depolymerization. Under the same reaction conditions, as shown
TABLE 1 | The major products from lignin conversion.

\begin{tabular}{|c|c|c|c|}
\hline Number & Name & Formula & $Y_{\text {Pd-zeolite }} / Y_{\text {zeolite }}$ \\
\hline$P_{1}$ & Phenol, 2-methoxy- & & 1.25 \\
\hline $\mathrm{P}_{2}$ & Phenol, 4-ethyl- & & 6.6 \\
\hline$P_{3}$ & Phenol, 4-ethyl-2-methoxy- & & 4.6 \\
\hline $\mathrm{P}_{4}$ & Phenol, 2-methoxy-4-propyl- & & 2.8 \\
\hline$P_{5}$ & Phenol, 2-methoxy-4-(1-propenyl)-,(E)- & & - \\
\hline$P_{6}$ & 4-Propyl-1,1'-diphenyl & & - \\
\hline $\mathrm{P}_{7}$ & Phenol, 2,6-dimethoxy-4-(2-propenyl)- & & 8.7 \\
\hline
\end{tabular}

$Y_{\text {Pd-zeolite: }}$ the yield of the product $x(x=1,2,3, \ldots, 7)$ from lignin conversion over

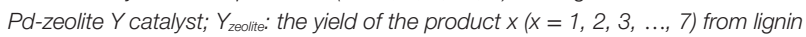
conversion over zeolite $Y$ catalyst; -: the value of $Y_{\text {Pd-zeolite }} / Y_{\text {zeolite }}$ was not calculated because the products from lignin conversion over zeolite were too low to be detected.

in Figure 4, zeolite $Y$ exhibited much lower catalytic activity than Pd-zeolite $\mathrm{Y}$ toward lignin degradation, while for $\mathrm{Pd}^{2+}$, almost no lignin depolymerization products were detected. From Table 1, for the major products $\left(\mathrm{P}_{2}, \mathrm{P}_{3}\right.$, and $\left.\mathrm{P}_{7}\right)$, Pd-zeolite $\mathrm{Y}$ led to at least four times higher of product yields $\left(\mathrm{P}_{2}, \mathrm{P}_{3}\right.$, and $\left.\mathrm{P}_{7}\right)$ than commercial zeolite, indicating that the addition of $\mathrm{Pd}$ significantly improved lignin depolymerization. Specially, $\mathrm{P}_{6}$ was only found in lignin depolymerization over Pd-zeolite but not over commercial zeolite.

Zeolites have been widely used as solid acid catalysts for lignin depolymerization. In this work, in situ generated Pd can be used as a new catalytic site for $\mathrm{C}-\mathrm{O}-\mathrm{C}$ bond cleavage in hydrogen atmosphere. With the addition of $\mathrm{Pd}$ as-prepared catalyst exhibited much higher activity than zeolite $\mathrm{Y}$ with sole $\mathrm{H}^{+}$-sites for lignin depolymerization, probably due to the accessorial depolymerization caused by $\mathrm{Pd}$ induced hydrogenolysis reaction. However, without the acidic support of zeolite Y, Pd alone showed negligible catalytic activity on lignin depolymerization. It indicated that zeolite Y dramatically improved the hydrogenolysis activity of Pd. Similar synergetic effects of acids and noble metals on lignin depolymerization were reported in previous studies (Laskar et al., 2014; Zhang et al., 2014a; Wang et al., 2015). Except for $\mathrm{OH}$ and $-\mathrm{OCH}_{3}$ bonds, no other $\mathrm{O}$-content functional groups was found on the side chains of the products. It suggested that $\mathrm{Pd}$-zeolite facilely removed "O" from the side chains of lignin through deoxygenation.

Based on the products in this work, potential reaction pathways to generate phenols and guaiacols are summarized in Figure 5. It was reported that the dehydration of $\mathrm{C} \alpha$ hydroxyl group in the side chains of lignin occurred first and formed a double carbon bond prior to $\beta$-O-4 bond cleavage (Jia et al., 2010). 


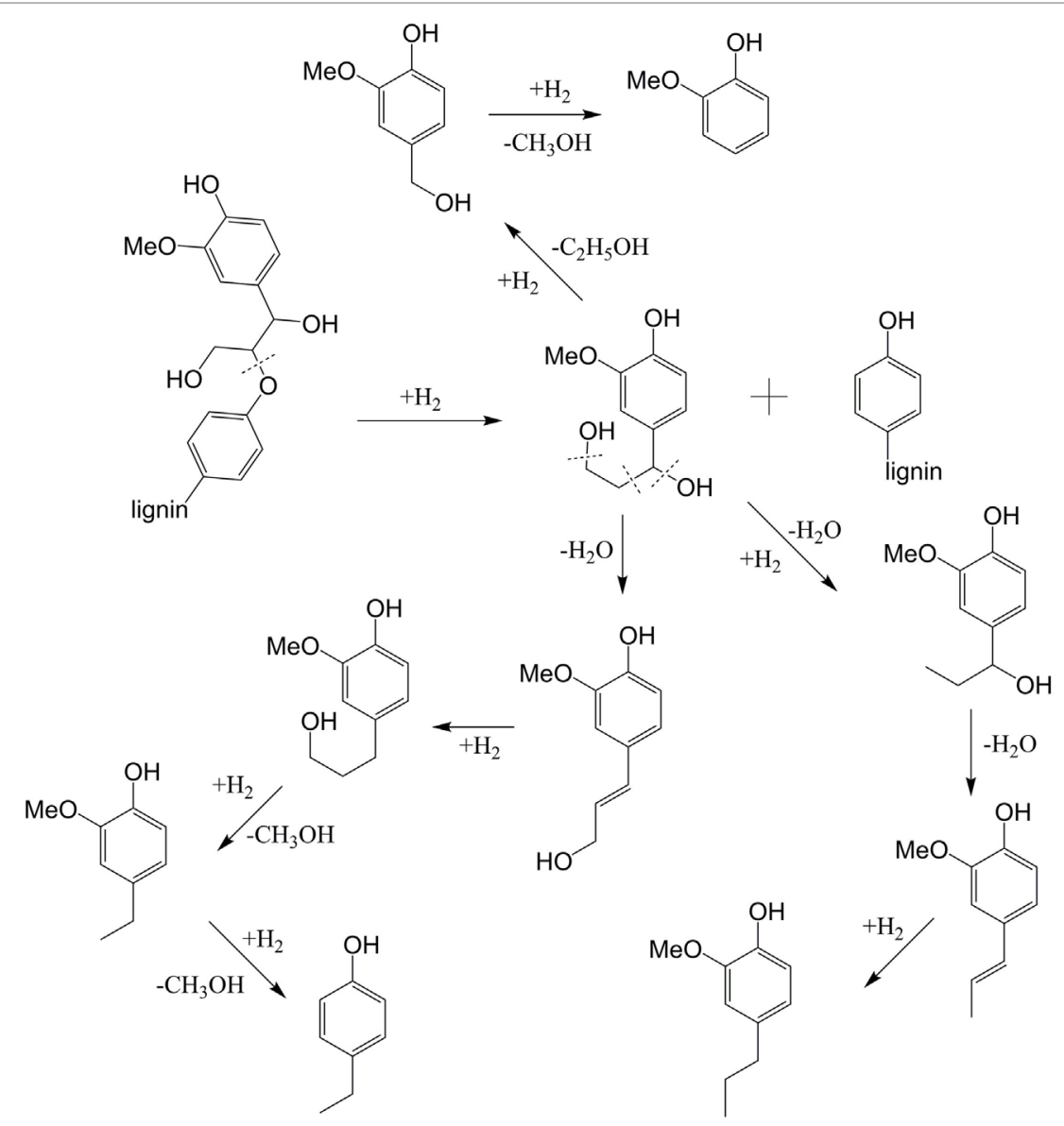

FIGURE $\mathbf{5}$ | Proposed reaction pathways for the formation of the major products from cleavage of the $\beta$-O-4 lignin.

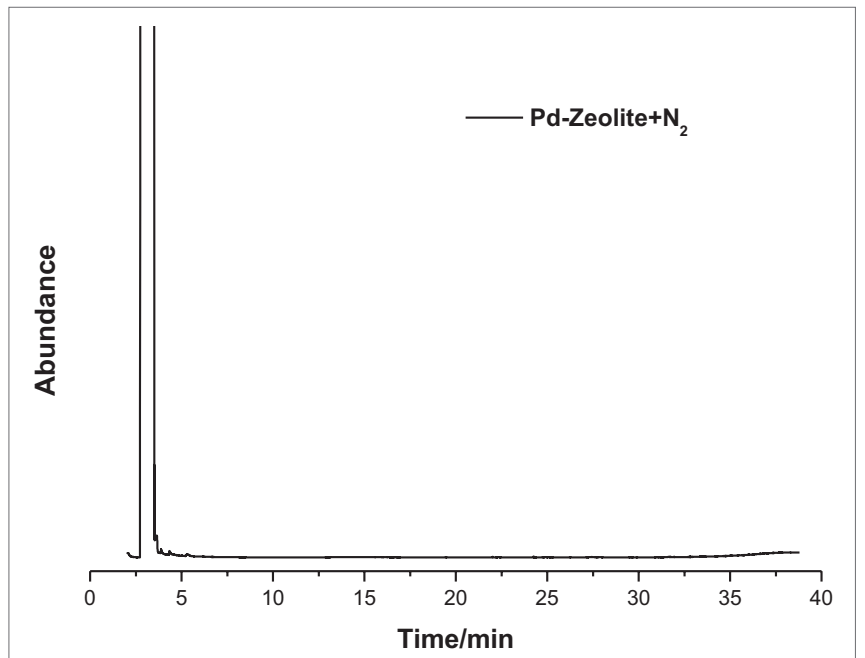

FIGURE 6 | GC-MS spectrum of the products from lignin depolymerization on $\mathrm{Pd}$-zeolite under the $\mathrm{N}_{2}$ atmosphere.

However, in this work, the cleavage of $\beta$-O- 4 bond can occur first because of the high hydrogen transferring ability of Pd, which is similar to the reaction path previously reported using Pt-based
TABLE 2 | Percentage of lignin aromatic inter-unit linkages and the selectivity of the major products via $\mathrm{Pd}$-zeolite $\mathrm{Y}$ catalysis.

\begin{tabular}{|c|c|c|c|c|c|c|c|c|c|c|}
\hline \multicolumn{4}{|c|}{$\begin{array}{l}\text { Lignin inter-unit linkages } \\
(\%)^{\mathrm{a}}\end{array}$} & \multicolumn{7}{|c|}{$\begin{array}{c}\text { Major products selectivity } \\
(\%)^{\mathrm{b}}\end{array}$} \\
\hline$\beta-0-4$ & $\beta-5$ & $\beta-\beta$ & $\beta-1$ & $\mathbf{P}_{1}$ & $\mathbf{P}_{2}$ & $\mathbf{P}_{3}$ & $\mathbf{P}_{4}$ & $\mathbf{P}_{5}$ & $\mathbf{P}_{6}$ & $\mathbf{P}_{7}$ \\
\hline 43 & 44 & 9 & 4 & 2.9 & 19.9 & 28 & 10.3 & 5.4 & 17.8 & 15.7 \\
\hline
\end{tabular}

and Ni-based catalysts (Zakzeski and Weckhuysen, 2011; Song et al., 2012). For the next step, three routes can react in parallel. One route is to generate guaiacol $\left(\mathrm{P}_{1}\right.$, Figure 5) through removing the hydroxyl-containing side chains. The second route is the formation of a double bond through dehydration reaction of $\mathrm{C} \alpha$, which can further generate $\mathrm{P}_{3}$ (Figure 5) by hydrogenation. The methoxy group linked on the benzene ring can be activated by the adjacent hydroxyl group and converted into hydroxyl through demethylation and further generate phenol structure $\mathrm{P}_{2}$ (Figure 5) (Peters et al., 2015). On the other hand, dehydroxylation may also happen on the $C \gamma$ position to generate $\mathrm{P}_{5}$ and $\mathrm{P}_{4}$ through further dehydration and hydrogenation reaction successively (Li et al., 2015). For product 6, biphenyl structure 


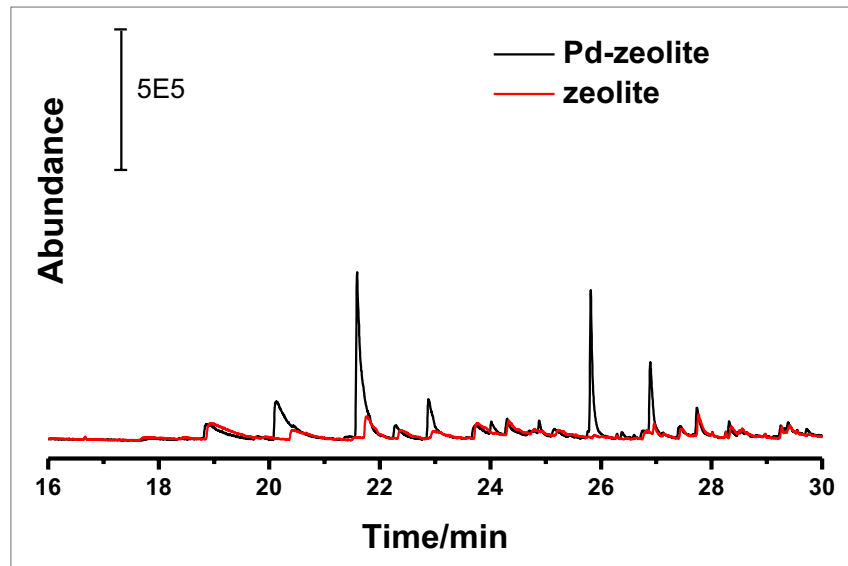

FIGURE 7 | GC-MS spectrum of the products from lignin depolymerization on $\mathrm{Pd}$-zeolite $\mathrm{Y}$ and zeolite at $180^{\circ} \mathrm{C}$.

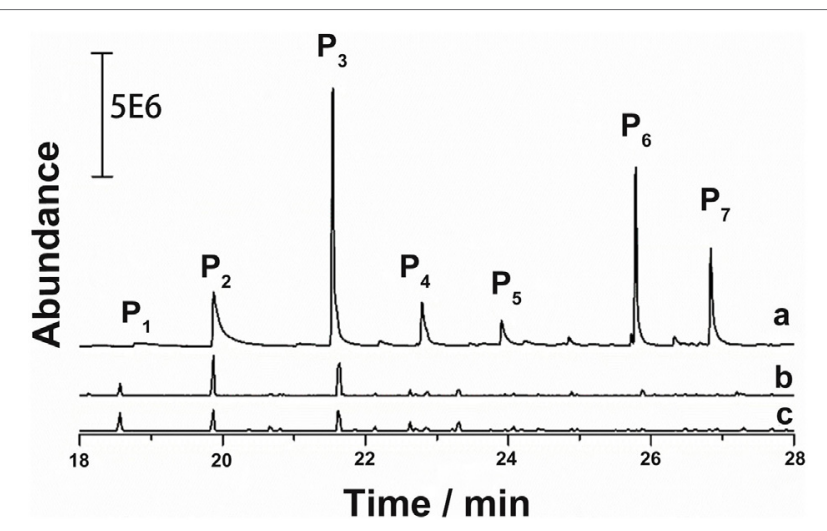

FIGURE 8 | GC-MS spectrum of the products from lignin depolymerization on Pd-zeolite (a) and commercial $\mathrm{Pd} / \mathrm{Al}_{2} \mathrm{O}_{3}$-zeolite composites catalysts [(b) $40 \mathrm{mg}$ of $\mathrm{Pd} / \mathrm{Al}_{2} \mathrm{O}_{3}+200 \mathrm{mg}$ of zeolite and (c) $4 \mathrm{mg}$ of $\mathrm{Pd} / \mathrm{Al}_{2} \mathrm{O}_{3}+200 \mathrm{mg}$ of zeolite] at $200^{\circ} \mathrm{C}$.

may be generated by coupling reaction between two aromatics (Hong et al., 2010).

Besides the catalysts as mentioned in the previous mechanism, hydrogen also plays a pivotal role in lignin depolymerization. From previous reports, lignin depolymerization in aqueous phase through hydrolysis by a solid acid catalyst is the dominant route (Taarning et al., 2011; Deepa and Dhepe, 2014). However, after Pd was loaded, results showed that hydrogenolysis was the principal route for bonds cleavage in hydrogen atmosphere at $200^{\circ} \mathrm{C}$. To further verify the significant role of hydrogen in this depolymerization process, lignin conversion without hydrogen was performed. As shown in Figure 6, under the same temperature and catalyst conditions, almost no product was detected in the $\mathrm{N}_{2}$ atmosphere. It is plausible that due to the existence of $\mathrm{Pd}$, the hydrogen-activation ability was significantly increased, thus further promoted lignin conversion. While in the $\mathrm{N}_{2}$ atmosphere, Pd-zeolite Y showed very low hydrolysis activity at the relatively low temperature. On the other hand, the product selectivity was also different on Pd-zeolite from that on zeolite because of the different hydrogen reactive ability. For example, about $18 \% \mathrm{P}_{6}$ (Table 2) was obtained from Pd-zeolite while almost no obvious $\mathrm{P}_{6}$ peak could be found in zeolite $\mathrm{Y}$ catalysis because $\mathrm{Pd}$ showed high activity toward coupling reactions to form biphenyls.

Furthermore, compositions of lignin inter-unit linkages obtained from NMR analysis and the major product selectivity are shown in Table 2. The alkali lignin used in this study was prepared and analyzed as reported in our previous work (Wang et al., 2015). Results suggested that the major products were divided into two categories: $\sim 82 \%$ phenols and $\sim 18 \%$ biphenyls. More than half (56.8\%) of the phenols were guaiacols, indicating the high preeminent selectivity of Pd-zeolite toward lignin degradation. The catalytic performance of Pd-zeolite $\mathrm{Y}$ and zeolite $\mathrm{Y}$ alone toward lignin degradation at even lower temperature $\left(180^{\circ} \mathrm{C}\right.$, initial $\mathrm{H}_{2}$ pressure $\left.3.5 \mathrm{MPa}\right)$ was studied. As shown in Figure 7, similar products selectivity was obtained on Pd-zeolite $\mathrm{Y}$ as compared with the reaction under $200^{\circ} \mathrm{C}$, and the products $\mathrm{P}_{1}-\mathrm{P}_{7}$ were clearly observed. Pd-zeolite $\mathrm{Y}$ still exhibited much better catalytic performance than zeolite at $180^{\circ} \mathrm{C}$. Results indicated that lignin was depolymerized at the temperature as low as $180^{\circ} \mathrm{C}$.

Lignin depolymerization on the state-of-the-art commercial $\mathrm{Pd} / \mathrm{Al}_{2} \mathrm{O}_{3}$-zeolite composites catalysts with equal amount of $\mathrm{Pd}$ and zeolite was tested to compare with the catalytic performance of Pd-zeolite Y. As shown in Figure 8, $4 \mathrm{mg}$ of $\mathrm{Pd} / \mathrm{Al}_{2} \mathrm{O}_{3}(0.2 \mathrm{mg}$ $\mathrm{Pd}$ ) with $200 \mathrm{mg}$ of zeolite displayed much lower catalytic activity than $\mathrm{Pd}$-zeolite. Generation of $\mathrm{P}_{1}-\mathrm{P}_{7}$ products remained similar even with 10 times $\mathrm{Pd} / \mathrm{Al}_{2} \mathrm{O}_{3}$ loading, which proves the high Pd atom efficiency of the Pd-zeolite Y catalyst developed in this study. From the abovementioned TEM images (Figure 1), it is observed that the particle size of the Pd is quite small, corresponding to the "atom economy" catalysis. The high catalytic activity of Pd-zeolite Y can be attributed to the high efficiency of surficial Pd atoms and the synergistic effects between Pd and zeolite Y.

\section{CONCLUSION}

Herein, we demonstrated that the Pd-zeolite Y catalysts prepared via the facile method were effective catalysts to depolymerize lignin to phenols and phenol derivatives at $99 \%$ yield. Due to the synergistic effects, Pd-zeolite led to much higher total yield of products than non-metalized zeolite or $\mathrm{Pd}^{2+}$ did when applied separately. In addition to catalysts, hydrogen was proved to have a critical role in lignin depolymerization. Although the as-prepared Pd-zeolite Y exhibited excellent catalytic performance toward the cleavage of ether bonds, its dehydroxylation and demethoxylation (on benzene) performance needs further improvement. Taking the advantage of the synergy effect of palladium and zeolite $\mathrm{Y}$, the Pd-zeolite Y catalyst in this study could be more cost effective and efficient than many other previously reported catalysts for conversion of lignin to value-added chemicals and fuels. 


\section{AUTHOR CONTRIBUTIONS}

YQ, HR, HW, MF, and BY conceptualized the work, designed experiment, analyzed data, and wrote the manuscript. YQ and HR conducted the experiment. All the authors have approved the manuscript and agreed with submission to Frontiers in Energy Research.

\section{ACKNOWLEDGMENTS}

Part of this work was conducted at the William R. Wiley Environmental Molecular Sciences Laboratory (EMSL), a national scientific user facility located at the Pacific Northwest National Laboratory (PNNL) and sponsored by the Department

\section{REFERENCES}

Alonso, D. M., Bond, J. Q., and Dumesic, J. A. (2010). Catalytic conversion of biomass to biofuels. Green Chem. 12, 1493-1513. doi:10.1039/c004654j

Ben, H., and Ragauskas, A. J. (2012). In situ NMR characterization of pyrolysis oil during accelerated aging. RSC Adv. 2, 12892-12898. doi:10.1039/ c2ra22616b

Choi, M., Lee, D. H., Na, K., Yu, B. W., and Ryoo, R. (2009). High catalytic activity of palladium(II)-exchanged mesoporous sodalite and NaA zeolite for bulky aryl coupling reactions: reusability under aerobic conditions. Angew. Chem. Int. Ed. Engl. 121, 3727-3730. doi:10.1002/anie.200806334

Deepa, A. K., and Dhepe, P. L. (2014). Solid acid catalyzed depolymerization of lignin into value added aromatic monomers. RSC Adv. 2014, 12625-12629. doi:10.1039/c3ra47818a

Deepa, A. K., and Dhepe, P. L. (2015). Lignin depolymerization into aromatic monomers over solid acid catalysts. ACS Catal. 5, 365-379. doi:10.1021/cs501371q

Hong, D. Y., Miller, S. J., Agrawal, P. K., and Jones, C. W. (2010). Hydrodeoxygenation and coupling of aqueous phenolics over bifunctional zeolite-supported metal catalysts. Chem. Commun. 46, 1038-1040. doi:10.1039/b918209h

Hui, K. S., Kwong, C. W., and Chao, C. Y. H. (2010). Methane emission abatement by Pd-ion-exchanged zeolite 13X with ozone. Energy Environ. Sci. 3, 1092-1098. doi:10.1039/c002669g

Jae, J., Tompsett, G. A., Lin, Y.-C., Carlson, T. R., Shen, J., Zhang, T., et al. (2010). Depolymerization of lignocellulosic biomass into fuel precursors: maximizing carbon efficiency by combining hydrolysis with pyrolysis. Energy Environ. Sci. 3, 358-365. doi:10.1039/b924621p

Jia, S., Cox, B. J., Guo, X., Zhang, Z. C., and Ekerdt, J. G. (2010). Cleaving the $\beta-\mathrm{O}-4$ bonds of lignin model compounds in an acidic ionic liquid, 1-H-3methylimidazolium chloride: an optional strategy for the degradation of lignin. ChemSusChem 3, 1078-1084. doi:10.1002/cssc.201000112

Jia, S., Cox, B. J., Guo, X., Zhang, Z. C., and Ekerdt, J. G. (2011). Hydrolytic cleavage of $\beta$-O-4 ether bonds of lignin model compounds in an ionic liquid with metal chlorides. Ind. Eng. Chem. Res. 50, 849-855. doi:10.1021/ie101884h

Kong, J., He, M., Lercher, J. A., and Zhao, C. (2015). Direct production of naphthenes and paraffins from lignin. Chem. Commun. 51, 17580-17583. doi:10.1039/ c5cc06828b

Laskar, D. D., Tucker, M. P., Chen, X., Helms, G. L., and Yang, B. (2014). Noblemetal catalyzed hydrodeoxygenation of biomass-derived lignin to aromatic hydrocarbons. Green Chem. 16, 897-910. doi:10.1039/c3gc42041h

Li, C., Zhao, X., Wang, A., Huber, G. W., and Zhang, T. (2015). Catalytic transformation of lignin for the production of chemicals and fuels. Chem. Rev. 21, 11559-11624. doi:10.1021/acs.chemrev.5b00155

Peters, J. E., Carpenter, J. R., and Dayton, D. C. (2015). Anisole and guaiacol hydrodeoxygenation reaction pathways over selected catalysts. Energy Fuels 29, 909-916. doi:10.1021/ef502551p

Ragauskas, A. J., Beckham, G. T., Biddy, M. J., Chandra, R., Chen, F., Davis, M. F., et al. (2014). Lignin valorization: improving lignin processing in the biorefinery. Science 344, 1246843. doi:10.1126/science.1246843

Scanion, J. T., and Willis, D. E. (1985). Calculation of flame ionization detector relative response factors using the effective carbon number concept. J. Chromatogr. Sci. 23, 333-340. doi:10.1093/chromsci/23.8.333 of Energy's Office of Biological and Environmental Research (BER). The authors also thank Dr. Zheming Wang and Ms. Marie S. Swita for insightful discussions.

\section{FUNDING}

This work was supported by the Seattle-based Joint Center for Aerospace Technology Innovation (JACTI), Sun Grant-U.S. Department of Transportation (DOT) Award \# T0013GA-Task 8, and U.S. Department of Energy DOE EERE Awards (DEEE0007104 and DE-EE0006112) with the Bioproducts, Science and Engineering Laboratory, Department of Biological Systems Engineering at Washington State University.

Singh, S. K., and Ekhe, J. D. (2014). Towards effective lignin conversion: HZSM-5 catalyzed one-pot solvolytic depolymerization/hydrodeoxygenation of lignin into value added compounds. RSC Adv. 4, 27971-27978. doi:10.1039/c4ra02968b

Singh, V. V., Jurado-Sánchez, B., Sattayasamitsathit, S., Orozco, J., Li, J., Galarnyk, M., et al. (2015). Multifunctional silver-exchanged zeolite micromotors for catalytic detoxification of chemical and biological threats. Adv. Funct. Mater. 25, 2147-2155. doi:10.1002/adfm.201500033

Song, Q., Wang, F., and Xu, J. (2012). Hydrogenolysis of lignosulfonate into phenols over heterogeneous nickel catalysts. Chem. Commun. 48, 7019-7021. doi:10.1039/c2cc31414b

Taarning, E., Osmundsen, C. M., Yang, X., Voss, B., Andersen, S. I., and Christensen, C.H. (2011).Zeolite-catalyzed biomass conversion to fuels and chemicals. Energy Environ. Sci. 4, 793-804. doi:10.1039/C004518G

Wang, H., Ruan, H., Feng, M., Qin, Y., Job, H., Luo, L., et al. (2017). One-pot process for hydrodeoxygenation of lignin to alkanes using Ru-based bimetallic and bifunctional catalysts supported on zeolite Y. ChemSusChem 10, 1846-1856. doi:10.1002/cssc.201700160

Wang, H., Ruan, H., Pei, H., Wang, H., Chen, X., Tucker, M. P., et al. (2015). Biomass-derived lignin to jet fuel range hydrocarbons via aqueous phase hydrodeoxygenation. Green Chem. 17, 5131-5135. doi:10.1039/C5GC01534K

Wang, H., Zhang, L., Deng, T., Ruan, H., Hou, X., Cort, J. R., et al. (2016). ZnCl induced catalytic conversion of softwood lignin to aromatics and hydrocarbons. Green Chem. 18, 2802-2810. doi:10.1039/C5GC02967H

Xu, C., Arancon, R. A., Labidi, J., and Luque, R. (2014). Lignin depolymerization strategies: towards valuable chemicals and fuels. Chem. Soc. Rev. 43, 7485-7500. doi:10.1039/C4CS00235K

Yang, Y., Fan, H., Song, J., Meng, Q., Zhou, H., Wu, L., et al. (2015). Free radical reaction promoted by ionic liquid: a route for metal-free oxidation depolymerization of lignin model compound and lignin. Chem. Commun. 51, 4028-4031. doi:10.1039/c4cc10394g

Zakzeski, J., and Weckhuysen, B. M. (2011). Lignin solubilization and aqueous phase reforming for the production of aromatic chemicals and hydrogen. ChemSusChem 4, 369-378. doi:10.1002/cssc.201000299

Zhang, W., Chen, J., Liu, R., Wang, S., Chen, L., and Li, K. (2014a). Hydrodeoxygenation of lignin-derived phenolic monomers and dimers to alkane fuels over bifunctional zeolite-supported metal catalysts. ACS Sustain. Chem. Eng. 2, 683-691. doi:10.1021/sc400401n

Zhang, J., Teo, J., Chen, X., Asakura, H., Tanaka, T., Teramura, K., et al. (2014b). A series of $\mathrm{NiM}(\mathrm{M}=\mathrm{Ru}, \mathrm{Rh}$, and $\mathrm{Pd})$ bimetallic catalysts for effective lignin hydrogenolysis in water. ACS Catal. 4, 1574-1583. doi:10.1021/cs401199f

Conflict of Interest Statement: The authors declare that the research was conducted in the absence of any commercial or financial relationships that could be construed as a potential conflict of interest.

Copyright (c) 2018 Qin, Wang, Ruan, Feng and Yang. This is an open-access article distributed under the terms of the Creative Commons Attribution License (CC BY). The use, distribution or reproduction in other forums is permitted, provided the original author(s) and the copyright owner are credited and that the original publication in this journal is cited, in accordance with accepted academic practice. No use, distribution or reproduction is permitted which does not comply with these terms. 